\title{
Cathodic fluidized granular activated carbon assisted-membrane bioelectrochemical reactor for wastewater treatment
}

\author{
Jian Li, Shuai Luo, Zhen He* \\ Department of Civil and Environmental Engineering, Virginia Polytechnic Institute and State University, Blacksburg, VA 24060, USA
}

\section{A R T I C L E I N F O}

\section{Article history:}

Received 16 April 2016

Received in revised form 1 June 2016

Accepted 5 June 2016

Available online 6 June 2016

\section{Keywords:}

Microbial fuel cell

Granular activated carbon

Membrane bioreactor

Bioenergy

Wastewater treatment

\begin{abstract}
A B S T R A C T
A membrane bioelectrochemical reactor (MBER) is a system integrating membrane filtration into microbial fuel cells. To control membrane fouling, fluidized granular activated carbon (GAC) was applied to the cathodic compartment of an MBER, which was examined for contaminant removal and electricity generation with low or medium strength synthetic wastewater. The MBER was operated for more than 160 days and achieved nearly $100 \%$ removal of organic compounds, regardless of presence/absence of GAC. However, fluidized GAC alleviated the membrane fouling issue and maintained transmembrane pressure (TMP) between 10 and $15 \mathrm{kPa}$ with $24 \mathrm{~g}$ of GAC. The presence of GAC also enhanced current generation from 200.3 to $256.0 \mathrm{~A} \mathrm{~m}^{-3}$, because some GAC might have functioned as a part of the cathodic electrode through physical contact with the electrode during fluidization. A higher aeration intensity could benefit both membrane fouling control (via scouring effect) and electricity generation (via oxygen supply), but required a higher energy demand. The energy consumption of the MBER including pumping and aeration was estimated to be $0.38 \mathrm{kWh} \mathrm{m}^{-3}$ or $0.25 \mathrm{kWh} \mathrm{kgCOD}^{-1}$, lower than that of conventional membrane bioreactors (MBRs). Those results encourage further investigation and development of the MBER technology to treat wastewater in an energy efficient way.
\end{abstract}

(C) 2016 Elsevier B.V. All rights reserved.

\section{Introduction}

Microbial fuel cell (MFC) technology offers a viable option for energy-efficient wastewater treatment with energy recovery $[1,2]$. In conventional MFCs, organics are biologically degraded by electrochemically-active bacteria (EAB), which are colonizing on an anodic electrode, and the generated electrons are migrating to a cathodic electrode via an external circuit $[3,4]$. Because of potential advantages in minimal aeration demand, less sludge production, and energy production, MFCs have been considered as an emerging approach for treating municipal or industrial waste streams [5-7]. In addition to organics removal and energy recovery, high-quality treated effluent could be achieved by integrating membrane separation with MFCs in either internal or external configurations [8]. The feasibility studies have been conducted by using either stainless steel or commercial hollow fiber polymeric membranes as an effective separating method for treating the MFC effluent, forming new systems termed as membrane bioelectrochemical reactors (MBERs) [9-11].

\footnotetext{
* Corresponding author.

E-mail address: zhenhe@vt.edu (Z. He).
}

Like conventional membrane bioreactors (MBRs), membrane fouling always poses a great challenge for MBER application and would result in high operational cost on fouling controls (e.g., off-line cleaning and periodic backwashing) [12]. To address the fouling issue, several strategies have been examined, such as modifying membrane surface property by coating polydopamine to enhance its hydrophobicity [13] and adjusting particle zetapotential to increase electro-repulsion force [14]. Those modified membranes would need long-term examination with actual wastewater for fouling situation. Less fouling could be achieved by connecting a membrane filtration process via an external connection with MFCs $[15,16]$. For example, a bench-scale air cathode MFC was connected with an anaerobic fluidized membrane bioreactor (AFMBR) to achieve a good quality of the final effluent [15]. In another study, a tubular MFC coupled with a membrane module had been operated for more than 100 days and in the absence of proper fouling control, the TMP could increase to $30 \mathrm{kPa}$ within only three days under the operation/relaxation mode [16]. Installing hollow fiber membranes in a cathodic compartment could be another way to minimize membrane fouling by taking advantage of organic removal in the anode and constant in-situ aeration in the cathode. It has been demonstrated that an MBER, which contained membrane bundle in its cathodic compartment, could treat both synthetic solution and cheese wastewater, but it was found 
that the TMP increased from 15 to $24 \mathrm{kPa}$ within nine days with aeration as the only fouling control method [17]. Therefore, aeration alone still has limited effects on fouling control and intensive aeration (to improve its fouling control) will result in increased energy consumption.

Granular activated carbon (GAC) has been applied in water and wastewater treatment for its superior characteristics of absorption, filterability, regeneration ability and low cost. A fluidized GAC bed can be effective to mitigate membrane fouling issue via a physical contact between GAC and membrane surface. For example, fluidized GAC bed was incorporated in an anaerobic membrane bioreactors (AnMBR), resulting in little need for physical and chemical cleaning of membrane module during its 120-day operation [18]. Such integration also gains more energy benefits comparing to conventional MBRs. Likewise, fluidized bed GAC was also applied to the anodic compartment of a tubular MBER to address membrane fouling issue, and it could significantly slow down the increase in transmembrane pressure (TMP), although its function as a partial anodic electrode was insignificant [19]. Therefore, applying fluidized bed GAC seems to be a promising solution to control membrane fouling in MBERs.

Intrigued by the energy advantage of MBER and the effectiveness of fluidized bed GAC on membrane fouling control, we proposed a two chambered MBER with fluidized GAC in the cathodic compartment for minimizing membrane fouling issue. Such an arrangement was based on the facts that the cathodic membrane module could have less fouling and the cathodic aeration may also be used to fluidize the GAC. The proposed MBER system would have some potential advantages including less GAC mass due to more turbulent movement with air bubbles, long retention time of oxygen molecules facilitated by GAC, a high surface area for aerobic treatment of high strength waste stream, and less effect of membrane cleaning on the anodic microbial activity. The specific objectives of this study were: (1) to demonstrate the feasibility of cathodic fluidized GAC in the MBER and its effects on membrane fouling control; (2) to examine the MBER treatment of the enhanced-strength wastewater; and (3) to investigate the impact of varied GAC mass and aeration intensity on the MBER performance.

\section{Materials and methods}

\subsection{MBER setup}

The MBER system was constructed as a tubular reactor $(23 \mathrm{~cm}$ long and $3.8 \mathrm{~cm}$ in diameter) made of anion exchange membrane (AEM-Ultrex AMI 7001, Membrane International. Inc, Glen Rock, New Jersey USA), as shown in Fig. 1. Carbon cloth (Zoltek Corporation, St. Louis, MO, USA) was used as the material for both the anodic and the cathodic electrodes. Before use, the carbon cloth was soaked in acetone solvent overnight and then heated for $30 \mathrm{~min}$ at $450{ }^{\circ} \mathrm{C}$ [20]. The cathodic electrode was coated with $\mathrm{Pt} / \mathrm{C}$ powder (10\% Etek, Somerest, NJ, USA) with a loading rate of $0.5 \mathrm{mg} \mathrm{Pt} \mathrm{cm}{ }^{-2}$. The finished cathodic electrode was installed along with inner surface of the AEM tube and supported by a plastic mesh (Industrial Netting, MN, USA), resulting in a net cathodic liquid volume of $270 \mathrm{~mL}$. The anodic electrode was plain carbon cloth and wrapped the AEM tube. A segment of PVC tube (an inner diameter of $5.1 \mathrm{~cm}$ ) was used as an outer cover, resulting in a net anodic volume of $75 \mathrm{~mL}$. The anodic and cathodic electrodes were connected to a $10 \Omega$ resistor (otherwise stated). Four 7 -cm PVDF hollow fiber ultrafiltration membranes (15,000 Da, Litree Purifying Technology Co. China) were glued by using epoxy to be a bundle and installed in the cathodic compartment. Twenty-four grams (otherwise stated) of granular activated carbon $(8 \times 30$ mesh Calgon Carbon
Corp, Pittsburgh, PA, USA) were added into the cathodic compartment as the fluidizing media.

\subsection{Operating conditions}

The MBER was operated at room temperature of $\sim 20^{\circ} \mathrm{C}$. Its anodic compartment was inoculated with the anaerobic sludge from a local wastewater treatment plant (Radford, VA, USA) and fed with a synthetic solution containing (per L of tap water): glucose $0.5 \mathrm{~g}$ or $1.5 \mathrm{~g} ; \mathrm{NH}_{4} \mathrm{Cl} 0.15 \mathrm{~g} ; \mathrm{NaCl} 0.5 \mathrm{~g} ; \mathrm{MgSO}_{4} 0.015 \mathrm{~g} ; \mathrm{CaCl}_{2} 0.02 \mathrm{~g}$; $\mathrm{KH}_{2} \mathrm{PO}_{4} 0.53 \mathrm{~g} ; \mathrm{K}_{2} \mathrm{HPO}_{4} 1.07 \mathrm{~g}$; and $1 \mathrm{~mL}$ trace elements [21]. The anolyte was recirculated at $40 \mathrm{~mL} \mathrm{~min}{ }^{-1}$. The MBER was operated in a full loop mode, in which the synthetic wastewater was fed into the anodic compartment first and then the anodic effluent flowed into the cathodic compartment, before the final effluent was extracted from the membrane module. The flowrate was controlled by a peristaltic pump to achieve a desired hydraulic retention time (HRT). The aeration was supplied by using an aquarium fishing pump, and the intensity of aeration was controlled by a mass flow controller (Aalborg. Inc, Orangeburg, NY, USA).

\subsection{Measurements and analysis}

The MBER voltage was recorded every 5 min by a digital multimeter (2700, Keithley Instruments, Cleveland, $\mathrm{OH}$ ). The $\mathrm{pH}$ was measured using a benchtop pH meter (Oakton Instruments, Vernon Hills, IL, USA). The conductivity was measured by a benchtop conductivity meter (Mettler-Toledo, Columbus, OH, USA). The concentration of chemical oxygen demand (COD) was measured by using a colorimeter according to the manufacturer's procedure (Hach DR/890, Hach Company, Loveland, CO, USA). Transmembrane pressure (TMP) was recorded manually and the average daily value was reported in this study. Turbidity was measured using a turbidimeter (DRT 100B, HF Scientific, Inc, Fort Meyers, FL, USA). The comparison of experimental data was analyzed by using two sample t-test.

\subsection{Energy balance}

Energy recovery was evaluated by normalized energy recovery

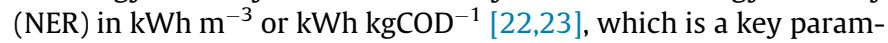
eter to assess the amount of energy that could be generated for treating one $\mathrm{m}^{3}$ of wastewater or one $\mathrm{kg}$ COD removed. The energy consumption by the pumping system (for feeding, recirculating, and membrane extracting) was estimated by using the following equation [18]:

$P=\frac{Q \gamma E}{1000}$

where $P$ is power requirement $(\mathrm{kW}), Q$ is flowrate $\left(\mathrm{m}^{3} \mathrm{~s}^{-1}\right), \gamma$ is 9800 $\left(\mathrm{N} \mathrm{m}^{-3}\right)$ and $E$ is head loss $\left(\mathrm{m} \mathrm{H}_{2} \mathrm{O}\right)$. The energy consumption by aeration was estimated according to a previous study [24]:

$p_{b}=\frac{p_{1} T \lambda}{273000 \varsigma(\lambda-1)} \times\left[\left(\frac{p_{2}}{p_{1}}\right)^{(1-(1 / \lambda))}-1\right] \times Q_{A}$

where $p_{b}$ is power consumption of a blower; $p_{1}$ and $p_{2}$ are the inlet (normally atmospheric) and outlet absolute pressures (Pa) respectively; $\varsigma$ is blower efficiency $(\sim 0.8) ; \lambda$ is aerator constant $(\sim 1.4) ; T$ is the inlet temperature $(\mathrm{K})$; and $Q_{A}$ is the volumetric flow rate of air $\left(\mathrm{m}^{3} \mathrm{~s}^{-1}\right)$. 


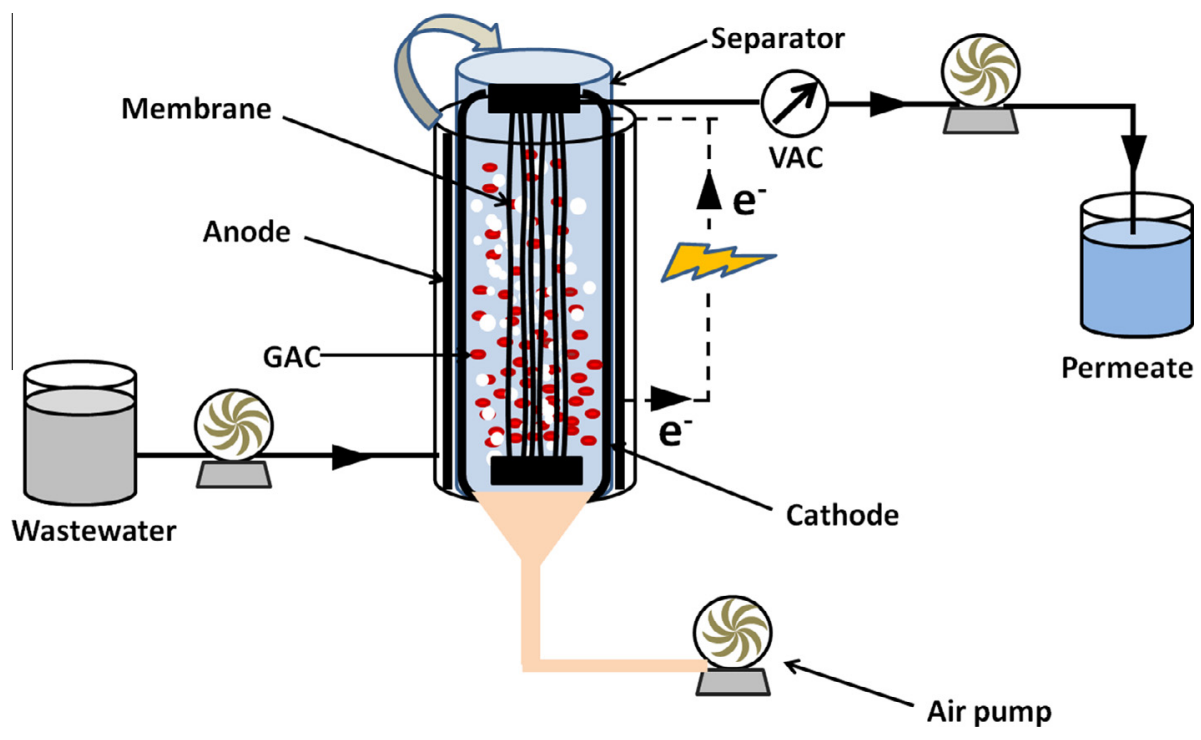

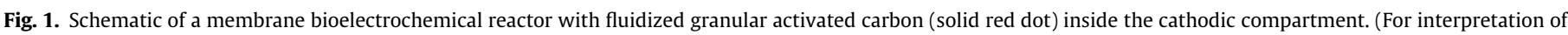
the references to color in this figure legend, the reader is referred to the web version of this article.)

\section{Results and discussions}

\subsection{Feasibility of cathodic fluidized GAC}

To examine the feasibility of this configuration, the MBER system was operated with the synthetic solution for 136 days, and its general performance is shown in Fig. 2. After about two-week startup, the data collection started on day 16 and the anolyte feeding rate was set at $0.21 \mathrm{~mL} \mathrm{~min}^{-1}$ resulting in an anodic HRT of $6 \mathrm{~h}$. The MBER generated a current density of $106.4 \mathrm{~A} \mathrm{~m}^{-3}$ on day 16 , which decreased gradually to $57.2 \mathrm{~A} \mathrm{~m}^{-3}$ on day 38 (Fig. 2A). Such a decrease in current generation was likely due to: (1) the residual organic contaminants could stimulate the heterotrophs growth on the cathodic electrode surface, which affected oxygen diffusion to the cathodic electrode, competed for oxygen with the cathodic electrode, and led to a rapid membrane fouling issue (Fig. 2B); and (2) the activity of electrochemically-active bacteria (EAB) could be inhibited by low $\mathrm{pH}(5.0-5.4)$ within the anodic compartment, resulted from the anaerobic fermentation process that produces volatile fatty acids. On day $39,24 \mathrm{~g}$ of GAC was added to the cathodic compartment, but this action did not increase current generation, which remained around $50 \mathrm{~A} \mathrm{~m}^{-3}$, likely due to the poor anodic performance with low $\mathrm{pH}$. On day 103 , the anolyte buffer strength was doubled (to $20 \mathrm{mM}$ ), and this boosted the current generation to $106.6 \mathrm{~A} \mathrm{~m}^{-3}$, suggesting that the low buffer capacity within the anodic compartment indeed limited the EAB activity.

The TMP variation is shown in Fig. 2B. It should be noted that neither periodic relaxation nor backwashing was applied here. From day 16 to 38 , the membrane module was operated without GAC, and aeration was the only method for fouling control. It was observed that the TMP increased from 5 to $25 \mathrm{kPa}$ during this period, indicating a cake layer was formed rapidly. After addition of GAC on day 39, the TMP quickly dropped to $15 \mathrm{kPa}$ and remained between 10 and $15 \mathrm{kPa}$ until day 62 when the GAC was removed from the cathodic compartment, indicating that the foulants on membrane surface were reversible and the fluidized GAC could be effective to alleviate fouling. This fouling alleviation benefited from several factors, including that the large surface area of GAC attracted biofilm formation, thereby reducing the biofoulant attachment to the membrane surface, physical abrasion of the membrane surface by fluidized GAC removed the foulants, and the altered hydrodynamics condition might enhance shear stress for foulants removal. When GAC was removed on day 63 , the membrane module demonstrated a slow/steady fouling, reflected by the low increase of the TMP from $13 \mathrm{kPa}$ on day 63 to $20 \mathrm{kPa}$ on day 98 and then a rapid increase from $20 \mathrm{kPa}$ on day 99 to $30 \mathrm{kPa}$ on day 105. Such TMP variation followed a classical membrane fouling process, in which absorption of soluble microbial products (SMPs) and extracellular polymerase substrate (EPS) could result in a rapid increase in TMP [25]. When GAC was added into the cathodic compartment again on day 106, the TMP did not decrease and remained at $30 \mathrm{kPa}$ for about ten days, suggesting the need for membrane cleaning due to irreversible fouling. On day 116, the membrane module was removed from the cathodic compartment and cleaned by using a soft brush to remove attached foulants and rinsing with tap water to detach the cake mass (based on the visual judgment). This cleaning decreased the TMP to $5 \mathrm{kPa}$ and GAC was added on day 126 for the following test.

The MBER system could effectively remove organic compounds, through sequential removal in the anodic compartment, the cathodic compartment, and hollow fiber membranes (Fig. 2C). In general, the MBER system achieved nearly $100 \%$ organic removal, regardless of the presence/absence of GAC in the cathodic compartment. The influent contained a TCOD concentration of $568.1 \mathrm{mg} \mathrm{L}^{-1}$, which was reduced to $152.3 \mathrm{mg} \mathrm{L}^{-1}$ after the anodic treatment that included both bioelectrochemical oxidation and possible aerobic oxidation due to oxygen diffusion from the cathode into the anode across the anion exchange membrane. The Coulombic efficiency was about $30 \%$, indicating that the majority of the removed organic compounds was not converted into electricity. The membrane permeates contained a COD concentration of $1.5 \mathrm{mg} \mathrm{L}^{-1}$. The turbidity of the membrane permeate was below 1.0 NTU.

On day 137, the glucose concentration was tripled to $1.5 \mathrm{~g} \mathrm{~L}^{-1}$ to mimic a medium strength wastewater, and to increase current generation, an external resistance of $0.1 \Omega$ was connected in the external circuit. To reduce energy consumption by aeration, a low aeration intensity of $10 \mathrm{cc} \mathrm{min}{ }^{-1}$ was applied at the beginning of the test. The MBER generated a current density of about $150 \mathrm{~A} \mathrm{~m}^{-3}$ (Fig. 3A). The membrane module exhibited a rapid fouling issue with the TMP increase from 7 to $28 \mathrm{kPa}$ within two days (Fig. 3B). After the off line cleaning, the TMP again increased quickly from 5 to $39 \mathrm{kPa}$ within four days. Thus, using $10 \mathrm{cc} \mathrm{min}{ }^{-1}$ 

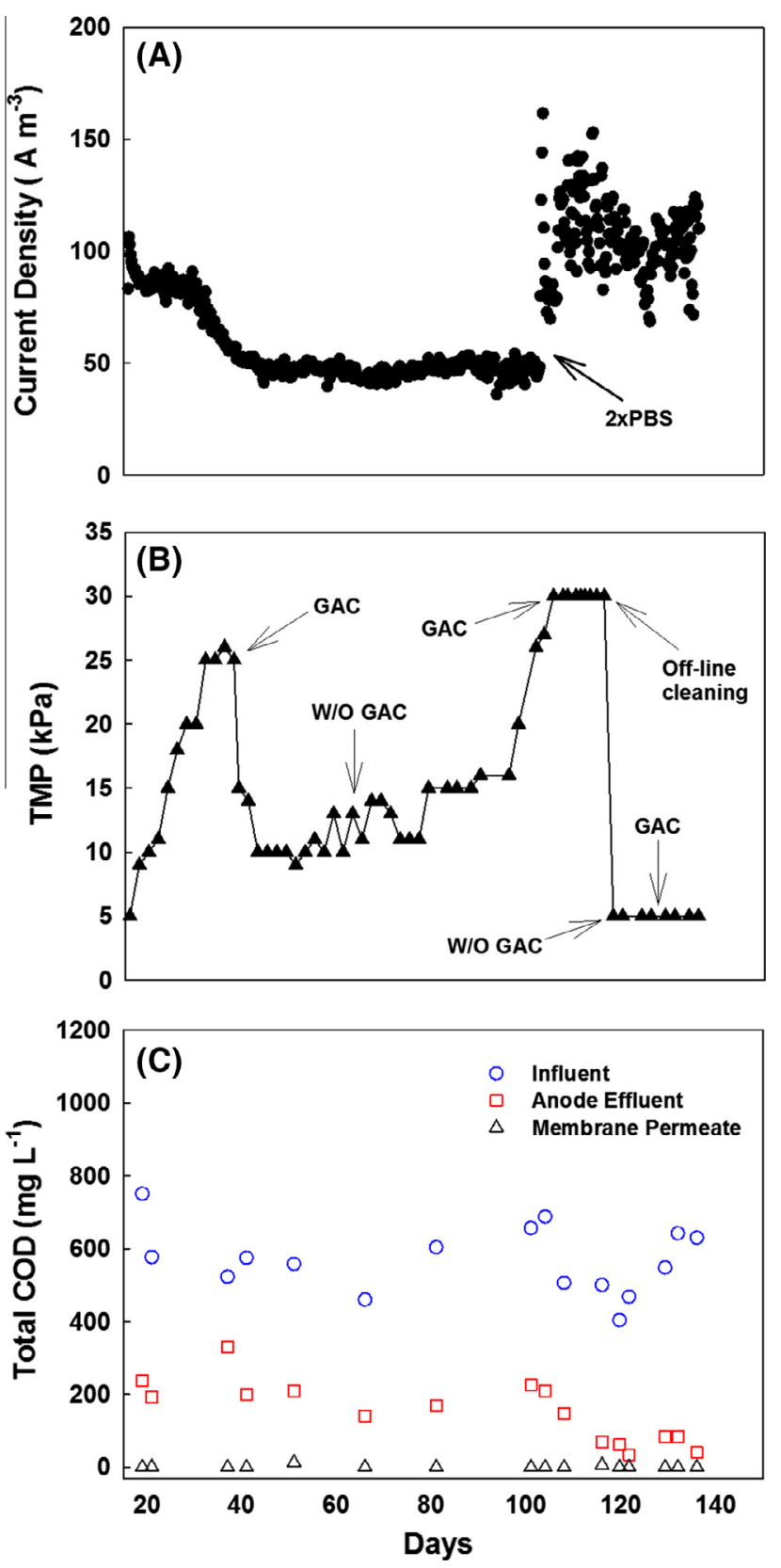

Fig. 2. The performance of MBER fed with a low-strength synthetic wastewater: (A) current density (external resistance of $10 \Omega$ ); (B) variation of transmembrane pressure (TMP); and (C) the concentrations of COD. The arrows indicate adding (GAC) or removing GAC (W/O GAC).

of aeration would not be an effective way to minimize the fouling issue, likely due to the weak shear stress effect on the membrane surface. On day 143 , the aeration intensity was increased to $50 \mathrm{cc} \mathrm{min}^{-1}$, which clearly benefited maintaining a low operational TMP: it took 20 days to increase the TMP from 5 to $35 \mathrm{kPa}$ (Fig. 3B). The current generation with $50 \mathrm{cc} \mathrm{min}^{-1}$ was not significantly higher than that with $10 \mathrm{cc} \mathrm{min}^{-1}$, indicating that oxygen supply was not limited by the relatively low aeration intensity but fouling control would benefit from a larger aeration intensity.

\subsection{The influence of aeration intensity}

To further understand the influence of aeration intensity, the MBER containing $10 \mathrm{~g}$ GAC in its cathodic compartment was oper-
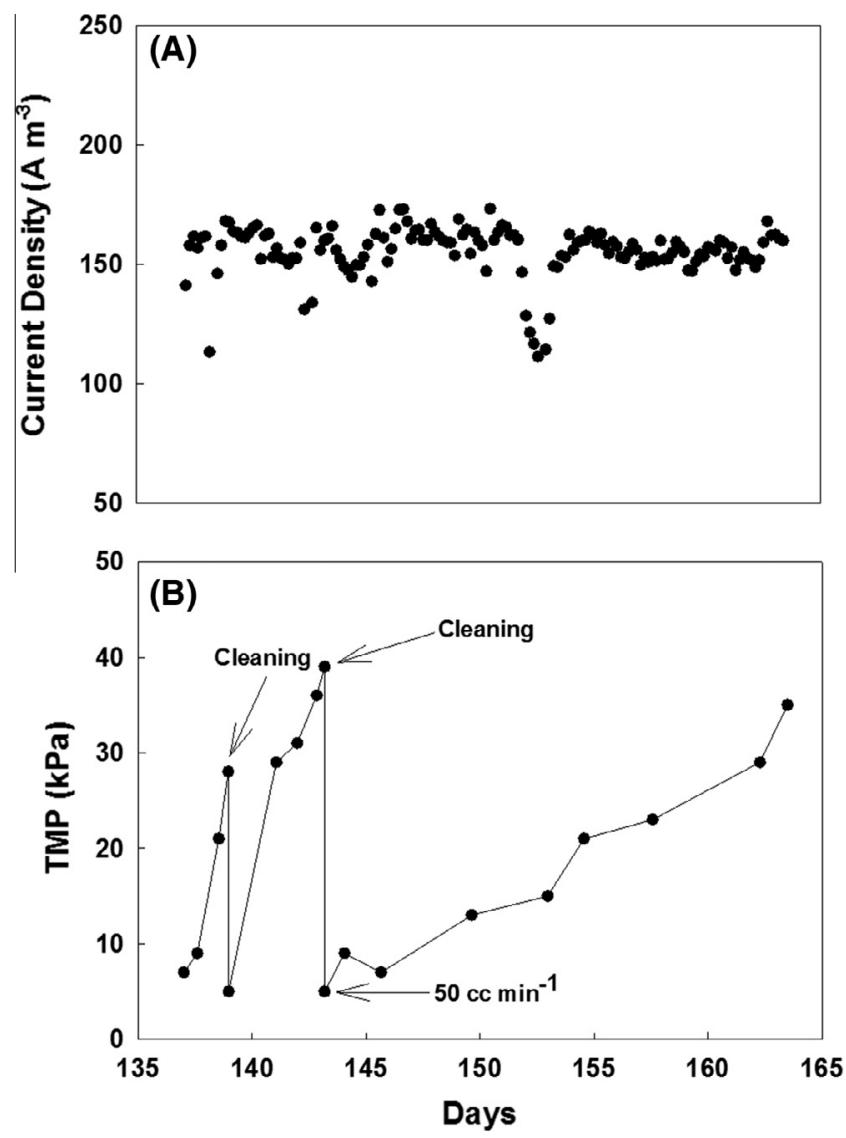

Fig. 3. The performance of MBER fed with a medium-strength synthetic wastewater: (A) current density (external resistance of $0.1 \Omega$ ) and (B) variation of transmembrane pressure (TMP).

ated under three aeration intensities, 50, 30 and $10 \mathrm{cc} \mathrm{min}^{-1}$, respectively. In this test, the MBER operation was not conducted in a loop mode: $1.5 \mathrm{~g} \mathrm{~L}^{-1}$ of glucose was used as a carbon source in the anode feeding solution, and $50 \mathrm{mM}$ PBS solution was used as the catholyte. An extra stainless steel mesh was inserted into the cathodic compartment to increase the contact area between the fluidized GAC and the electron collector. The MBER generated a current density of $247.0 \pm 4.9 \mathrm{~A} \mathrm{~m}^{-3}$ (across $0.1 \Omega$ ) under an aeration intensity of $50 \mathrm{cc} \mathrm{min}^{-1}$ without GAC addition (Fig. 4A). Adding and fluidizing $10 \mathrm{~g}$ of GAC enhanced the current density to $256.0 \pm 7.1 \mathrm{~A} \mathrm{~m}^{-3}$ under the same aeration intensity $(p<0.05)$, indicating that aerobic fluidized GAC could improve cathodic performance, likely due to (1) GAC might have partially functioned as cathodic electrodes; and (2) GAC motion might have created finer oxygen bubbles for more effective transport to and utilization by the cathodic electrode. Reducing the aeration intensity to $30 \mathrm{cc} \mathrm{min}{ }^{-1}$ eliminated the difference in current generation between the MBER without GAC $\left(232.2 \pm 12.0 \mathrm{~A} \mathrm{~m}^{-3}\right)$ and the one with GAC $\left(235.7 \pm 7.4 \mathrm{~A} \mathrm{~m}^{-3}\right)(p>0.05)$. Interestingly, this difference appeared again after the aeration intensity was reduced to $10 \mathrm{cc} \mathrm{min}^{-1}$ : the current density of $221.7 \pm 5.8 \mathrm{~A} \mathrm{~m}^{-3}$ in the presence of fluidized GAC was significantly higher than $200.3 \pm 24.1 \mathrm{~A} \mathrm{~m}^{-3}$ from the MBER without GAC $(p<0.05)$. The low aeration intensity of $10 \mathrm{cc} \mathrm{min}^{-1}$ allowed the GAC to pack at the bottom part of reactor, creating a "filtration process" for air to pass through and produce finer air bubble to enhance gasliquid interfacial mass transfer coefficient that may promote oxygen migration towards cathodic electrode surface [26]. Unlike the electricity generation with $24 \mathrm{~g}$ of GAC in Section 3.1, the low amount of GAC at $10 \mathrm{~g}$ led to higher current generation at 

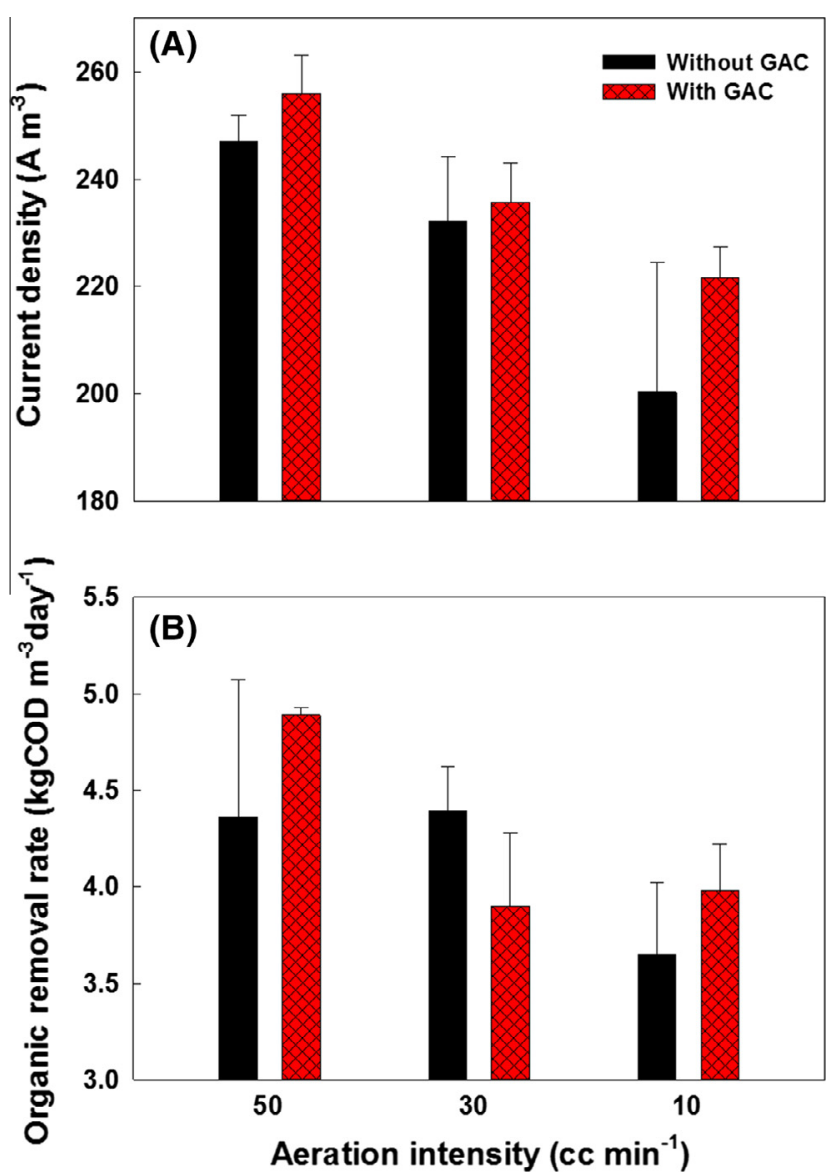

Fig. 4. The performance of MBER with different aeration intensity in the cathodic compartment with or without GAC: (A) current generation and (B) anodic organic removal rate (anodic compartment only).

$50 \mathrm{cc} \mathrm{min}^{-1}$ than that at $10 \mathrm{cc} \mathrm{min}{ }^{-1}$, possibly related to the fact that a stronger aeration intensity could better fluidize GAC and have some GAC acting as part of the cathode electrode (when GAC particles were in contact with the cathode electrode during fluidization). The aeration intensity had significant effects on the anodic organic removal rate, which was related to current generation; however, there was no significant difference in overall organic removal between the MBER with and without GAC (Fig. 4B).

When the amount of GAC was increased from 10 to $24 \mathrm{~g}$, the MBER produced a current density of $243.2 \pm 7.8 \mathrm{~A} \mathrm{~m}^{-3}$ with the $10 \mathrm{cc} \mathrm{min}^{-1}$ aeration, significantly higher than that of $10 \mathrm{~g} \mathrm{GAC}$ $\left(221.7 \pm 5.8 \mathrm{~A} \mathrm{~m}^{-3}\right)$, confirming that GAC could act as a part of the cathodic electrode and more GAC would accelerate the cathodic reaction for more electron consumption. One hypothesis was that the high GAC loading may allow even lower aeration intensity, due to higher surface area of the cathodic electrode. Thus, the aeration intensity was further reduced to 5 and $2 \mathrm{cc} \mathrm{min}^{-1}$, resulting current generation of $256.2 \pm 25.7$ and $251.7 \pm 19.9 \mathrm{~A} \mathrm{~m}^{-3}$, respectively (not significantly different from that of $10 \mathrm{cc} \mathrm{min}^{-1}$, $p>0.05$ ); however, the current densities at such low aeration intensities were still higher than that with $10 \mathrm{~g}$ GAC at higher aeration intensities.

\subsection{Energy consumption}

The energy production of the MBER was low, at $0.001 \mathrm{kWh} \mathrm{m}^{-3}$ or $0.001 \mathrm{kWh} \mathrm{kgCOD}^{-1}$ when $1.5 \mathrm{~g} \mathrm{~L}^{-1}$ glucose was used. This was

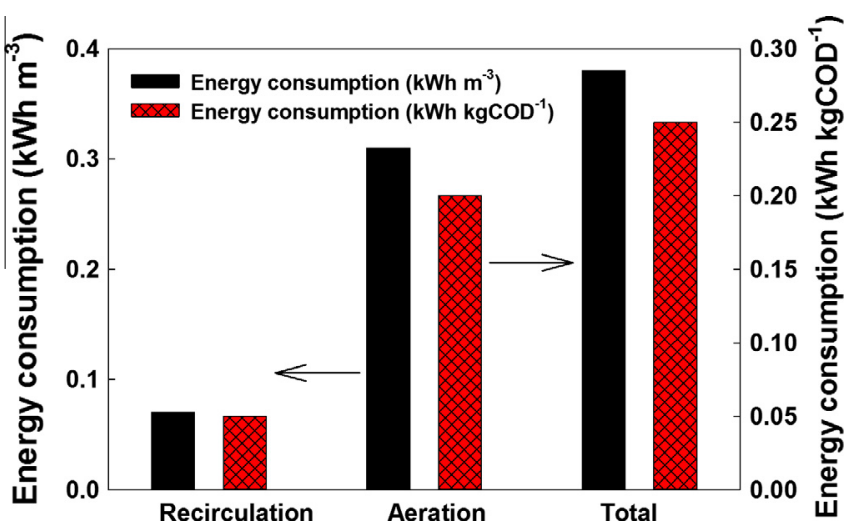

Fig. 5. The energy consumption of the MBER under the condition of the recirculation rate of $40 \mathrm{~mL} \mathrm{~min}^{-1}$, aeration intensity of $50 \mathrm{cc} \mathrm{min}{ }^{-1}$ and influent TCOD of $1.5 \mathrm{~g} \mathrm{~L}^{-1}$ glucose.

largely related to the low external resistance of $0.1 \Omega$, which led to high current generation but very low power production. To obtain the maximum power output, the external resistance needs to be close to the internal resistance of the system. However, its energy consumption was also low, compared with conventional MBR systems. At the highest aeration intensity of $50 \mathrm{cc} \mathrm{min}^{-1}$, the specific energy consumption for recirculation and aeration was 0.07 and $0.31 \mathrm{kWh} \mathrm{m}^{-3}$, respectively, resulting in total energy consumption of $0.38 \mathrm{kWh} \mathrm{m}^{-3}$ (Fig. 5). When expressed as per $\mathrm{kg}$ COD removed, the total energy consumption was $0.25 \mathrm{kWh} \mathrm{kgCOD}^{-1}$, including $0.05 \mathrm{kWh} \mathrm{kgCOD}^{-1}$ by the recirculation and $0.20 \mathrm{kWh} \mathrm{kgCOD}^{-1}$ by the aeration. For comparison, the specific energy consumption of MBRs varied from 0.8 to $2.4 \mathrm{kWh} \mathrm{m}^{-3}$, or 2.6 to $5.2 \mathrm{kWh} \mathrm{kgCOD}^{-1}$ for treating municipal wastewater [27]. When treating medium strength wastewater such as food process wastewater, MBRs could have a specific energy demand of 2.0$3.6 \mathrm{kWh} \mathrm{m}^{-3}$ and $1.0 \mathrm{kWh} \mathrm{kgCOD}^{-1}$ [28]. Thus, the present MBER could be more advantageous in low energy demand compared to conventional MBR.

\subsection{Outlook}

The developed MBER has several potential advantages for application in wastewater treatment. By adding and fluidizing GAC in the cathodic compartment, membrane fouling can be slowed down and thus less fouling control/cleaning will be needed, resulting in less maintenance requirement. The added GAC could act as a part of the cathodic electrode through periodic contact between GAC and the electron collector during fluidization, and this will increase electricity generation through improving cathode reactions and/or increasing the surface area of the cathodic electrode. The large surface area of GAC will also accommodate aerobic treatment of wastewater and enhance the effluent quality. The fluidized GAC may help create small air bubbles that will benefit oxygen transfer to the cathodic electrode, but this warrants further investigation. Low energy consumption will make the proposed MBER more advantageous for wastewater treatment.

There are several challenges to further develop this MBER and should be addressed with more studies. First, the production of electrical energy must be further improved. In addition to using a higher external resistance, this may also be accomplished by improving the anodic performance (e.g., larger surface area of the electrode and selected microbial community with stronger electrochemical activities). Because fluidized GAC could function as a part of the cathodic electrode, efficient transport of electrons to GAC for oxygen reduction reaction will help with energy production. 
Second, the energy consumption should be further reduced through optimizing the operation, for example, reducing electrolyte recirculation flowrate can greatly reduce the energy consumption [16]. In addition, aeration intensity may be decreased for lower energy need and this could be compensated by using more GAC or using an intermittent aeration strategy by taking advantage of the capacitance of fluidized GAC on the cathodic reduction reaction. There could be a trade-off between decreasing aeration and increasing membrane fouling (due to less scouring effect). Third, the integrity and morphology of GAC will play a key role in stable operation of the fluidization, and material and size of GAC will also affect the performance. Fourth, although nitrogen removal was not a key focus in the present work, it is expected that using a bioelectrochemical system could provide a solution for nutrient removal/recovery in less carbon footprint $[29,30]$. Fifth, although the tested COD was only between 500 and $1500 \mathrm{mg} \mathrm{L}^{-1}$, high fouling tendency waste such as sewage sludge could be investigated in later study [31]. Last but not the least, scaling up MBER is a critical step to transform the findings from bench-scale systems to a more practical technology and will allow us to conduct analyses such as capital cost [32]. We have successfully scaled up microbial fuel cell systems to a scale of $200 \mathrm{~L}$ and a microbial desalination cell system to $100 \mathrm{~L}[33,34]$, both of which will provide valuable experience for scaling up the MBER.

\section{Conclusions}

The present study has demonstrated the feasibility of a membrane bioelectrochemical reactor with fluidized granular activated carbon in its cathodic compartment for treating synthetic wastewater at a bench scale. The fluidized GAC exhibited multiple functions including membrane fouling control media, a part of the cathodic electrode, and carriers of aerobic treatment. The aeration intensity could affect both membrane fouling and electricity generation, and a higher amount of GAC might compensate for lower aeration intensity. The MBER has a lower energy demand for its operation, compared with conventional MBR systems. Future studies will need to address several challenges for MBER development, including improving energy production, further reducing energy consumption, optimizing the aeration, examining the GAC integrity, and MBER scaling up.

\section{Acknowledgements}

This research was financially supported by a grant from the US National Science Foundation (award \#1358145). Shuai Luo was supported by a fellowship from Water INTERface IGEP, Graduate School of Virginia Tech.

\section{References}

[1] W.W. Li, H.Q. Yu, Z. He, Towards sustainable wastewater treatment by using microbial fuel cells-centered technologies, Energy Environ. Sci. 7 (2014) 911924.

[2] A. Karluvalı, E.O. Köroğlu, N. Manav, A.Y. Çetinkaya, B. Özkaya, Electricity generation from organic fraction of municipal solid wastes in tubular microbial fuel cell, Sep. Purif. Technol. 156 (2015) 502-511.

[3] B.E. Logan, B. Hamelers, R. Rozendal, U. Schröder, J. Keller, S. Freguia, P. Aelterman, W. Verstraete, K. Rabaey, Microbial fuel cells: methodology and technology, Environ. Sci. Technol. 40 (2006) 5181-5192.

[4] M. Grzebyk, G. Poźniak, Microbial fuel cells (MFCs) with interpolymer cation exchange membranes, Sep. Purif. Technol. 41 (2005) 321-328.

[5] F. Zhang, Z. Ge, J. Grimaud, J. Hurst, Z. He, Long-term performance of liter-scale microbial fuel cells treating primary effluent installed in a municipal wastewater treatment facility, Environ. Sci. Technol. 47 (2013) 4941-4948.

[6] J. Li, Y. Zhu, L. Zhuang, Y. Otsuka, M. Nakamura, B. Goodell, T. Sonoki, Z. He, A novel approach to recycle bacterial culture waste for fermentation reuse via a microbial fuel cell-membrane bioreactor system, Bioprocess Biosyst. Eng. 38 (2015) 1795-1802.
[7] K. Rabaey, W. Verstraete, Microbial fuel cells: novel biotechnology for energy generation, Trends Biotechnol. 23 (2005) 291-298.

[8] H. Yuan, Z. He, Integrating membrane filtration into bioelectrochemical systems as next generation energy-efficient wastewater treatment technologies for water reclamation: a review, Bioresour. Technol. 195 (2015) 202-209.

[9] Y.K. Wang, G.P. Sheng, W.W. Li, Y.X. Huang, Y.Y. Yu, R.J. Zeng, H.Q. Yu, Development of a novel bioelectrochemical membrane reactor for wastewater treatment, Environ. Sci. Technol. 45 (2011) 9256-9261.

[10] Y.P. Wang, X.W. Liu, W.W. Li, F. Li, Y.K. Wang, G.P. Sheng, R.J. Zeng, H.Q. Yu, A microbial fuel cell-membrane bioreactor integrated system for cost-effective wastewater treatment, Appl. Energy 98 (2012) 230-235.

[11] Z. Ge, Q. Ping, Z. He, Hollow-fiber membrane bioelectrochemical reactor for domestic wastewater treatment, J. Chem. Technol. Biotechnol. 88 (2013) 1584-1590.

[12] T.-T. Nguyen, X.-T. Bui, T.-D.-H. Vo, D.-D. Nguyen, P.-D. Nguyen, H.-L.-C. Do, H.H. Ngo, W. Guo, Performance and membrane fouling of two types of laboratory-scale submerged membrane bioreactors for hospital wastewater treatment at low flux condition, Sep. Purif. Technol. 165 (2016) 123-129.

[13] K.Y. Kim, E. Yang, M.Y. Lee, K.J. Chae, C.M. Kim, I.S. Kim, Polydopamine coating effects on ultrafiltration membrane to enhance power density and mitigate biofouling of ultrafiltration microbial fuel cells (UF-MFCs), Water Res. 54 (2014) 62-68

[14] Y. Tian, H. Li, L. Li, X. Su, Y. Lu, W. Zuo, J. Zhang, In-situ integration of microbial fuel cell with hollow-fiber membrane bioreactor for wastewater treatment and membrane fouling mitigation, Biosens. Bioelectron. 64 (2015) 189-195.

[15] L. Ren, Y. Ahn, B.E. Logan, A two-stage microbial fuel cell and anaerobic fluidized bed membrane bioreactor (MFC-AFMBR) system for effective domestic wastewater treatment, Environ. Sci. Technol. 48 (2014) 4199-4206.

[16] J. Li, G. Rosenberger, Z. He, Integrated experimental investigation and mathematical modeling of a membrane bioelectrochemical reactor with an external membrane module, Chem. Eng. J. 287 (2016) 321-328.

[17] J. Li, Z. Ge, Z. He, Advancing membrane bioelectrochemical reactor (MBER) with hollow-fiber membranes installed in the cathode compartment, J. Chem. Technol. Biotechnol. 89 (2014) 1330-1336.

[18] J. Kim, K. Kim, H. Ye, E. Lee, C. Shin, P.L. McCarty, J. Bae, Anaerobic fluidized bed membrane bioreactor for wastewater treatment, Environ. Sci. Technol. 45 (2011) 576-581.

[19] J. Li, Z. Ge, Z. He, A fluidized bed membrane bioelectrochemical reactor for energy-efficient wastewater treatment, Bioresour. Technol. 167 (2014) 310315.

[20] X. Wang, S. Cheng, Y. Feng, M.D. Merrill, T. Saito, B.E. Logan, Use of carbon mesh anodes and the effect of different pretreatment methods on power production in microbial fuel cells, Environ. Sci. Technol. 43 (2009) 6870-6874.

[21] Z. He, N. Wagner, S.D. Minteer, L.T. Angenent, An upflow microbial fuel cell with an interior cathode: assessment of the internal resistance by impedance spectroscopy, Environ. Sci. Technol. 40 (2006) 5212-5217.

[22] Z. Ge, J. Li, L. Xiao, Y. Tong, Z. He, Recovery of electrical energy in microbial fuel cells: brief review, Environ. Sci. Technol. Lett. 1 (2013) 137-141.

[23] L. Xiao, Z. Ge, P. Kelly, F. Zhang, Z. He, Evaluation of normalized energy recovery (NER) in microbial fuel cells affected by reactor dimensions and substrates, Bioresour. Technol. 157 (2014) 77-83.

[24] B. Verrecht, S. Judd, G. Guglielmi, C. Brepols, J.W. Mulder, An aeration energy model for an immersed membrane bioreactor, Water Res. 42 (2008) 4761 4770.

[25] P.K. Gkotsis, D.C. Banti, E.N. Peleka, A.I. Zouboulis, P.E. Samaras, Fouling issues in membrane bioreactors (MBRs) for wastewater treatment: Major mechanisms, prevention and control strategies, Processes 2 (2014) 795-866.

[26] S.D. Kim, Y. Kang, Heat and mass transfer in three-phase fluidized-bed reactors-an overview, Chem. Eng. Sci. 52 (1997) 3639-3660.

[27] B. Barillon, S.M. Ruel, C. Langlais, V. Lazarova, Energy efficiency in membrane bioreactors, Water Sci. Technol. 67 (2013) 2689-2691.

[28] D. Bolzonella, F. Fatone, P. Pavan, F. Cecchi, Application of a membrane bioreactor for winery wastewater treatment, Water Sci. Technol. 62 (2010) 2754-2759.

[29] Y. Zhang, I. Angelidaki, Recovery of ammonia and sulfate from waste streams and bioenergy production via bipolar bioelectrodialysis, Water Res. 85 (2015) $177-184$.

[30] Y. Zhang, I. Angelidaki, Counteracting ammonia inhibition during anaerobic digestion by recovery using submersible microbial desalination cell, Biotechnol. Bioeng. 112 (2015) 1478-1482.

[31] Y. Zhang, L.G. Olias, P. Kongjan, I. Angelidaki, Submersible microbial fuel cell for electricity production from sewage sludge, Water Sci. Technol. 64 (2011) 50-55.

[32] Y. Zhang, I. Angelidaki, Microbial electrochemical systems and technologies: it is time to report the capital costs, Environ. Sci. Technol. 50 (2016) 5432-5433.

[33] Z. Ge, Z. He, Long-term performance of a 200 liter modularized microbial fuel cell system treating municipal wastewater: treatment, energy, and cost, Environ. Sci.: Water Res. Technol. 2 (2016) 274-281.

[34] F. Zhang, Z. He, Scaling up microbial desalination cell system with a postaerobic process for simultaneous wastewater treatment and seawater desalination, Desalination 360 (2015) 28-34. 